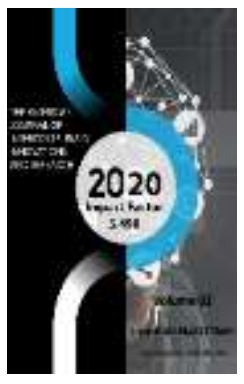

Journal Website: http://usajournalshub.c om/index,php/tajiir

Copyright: Original content from this work may be used under the terms of the creative commons attributes 4.0 licence.

\section{What Happens In Educational Institutes When Educators Use Social Network Sites (SNS)? A Case Study From Thessaly}

\author{
Vasileios Gougas \\ PhD Student, Faculty Of Primary And Preschool Education, St. Kliment Ohridski University Of \\ Sofia, Bulgaria \\ Lucia Malinova \\ Professor, Faculty Of Primary And Preschool Education, St. Kliment Ohridski University Of \\ Sofia, Bulgaria
}

\title{
ABSTRACT
}

These days, educators, not only in Greece but also throughout the world, seem to use the Social Network Sites extensively. The aim of this particular report is the formation of a questionnaire that focuses on the effect that comes with the extensive use of the SNS. Particularly, Thessaly-based educators participated in the conduct of this survey. The results have shown that the use of the SNS has gradually declined and that those who still recourse to them do that in order to socialize.

\section{KEYWORDS}

SNS, hedonic, motivation, consequences, procrastination, social network, Facebook, Interne

\section{INTRODUCTION}

Social Network Sites (SNS), like the Facebook, or Twitter, have become an integral part and play a significant role in the lives of millions of people (Somerville \& Brady, 2019). They constitute a technological form that allows the social interaction in an online environment (Lenhart et al., 2015). Apart from that, they, also, constitute one of the main forms of entertainment, access to and dissemination of information, and a problem-solving tool for both individuals and groups of people.

According to Boyd and Ellison (2007), the SNS allow their users to form and manage a profile through which they can connect with others in order to exchange ideas and content. Kuss and Griffiths (2017) state that these sites are a type of virtual communities that permit the creation of public profiles through which they can 
interact with their real-life friends, meet others that share the same interests, chat, share pictures and videos, play online games, and even gamble. They are considered to be a global phenomenon that is increasingly gaining in popularity. Their users can access them via different devices, such as mobile phones or personal computers.

\section{LITERATURE REVIEW}

Research has shown that the use of the SNS can take the form of escapism that is a way to escape reality, as well that of entertainment, information sharing and social relations (Oliver \& Raney, 2011). Lin et al., 2014; Cao et al., 2005; De Wulf et al., 2006, have proven that the use of the SNS is highly linked with pleasure, enjoyment and recreation. Furthermore, the usability of the SNS constitutes an important factor in their constant use (Mantymaki and Riemer, 2011). A number of studies that focused on the use of the SNS for consumerism have demonstrated that the different types of informational systems and the varied use of the SNS affect usability and contentment (Kim et al., 2012; Lopez and Ruiz, 2011).

Socializing involves keeping in contact with people who you share the same interests with, as well as connecting with them (Cacioppo \& Patrick, 2008). Consequently, those users that are subsequently motivated, are highly likely to engage in activities that entail some commitment (Ryan \& Deci, 2000), such as online content sharing (Cheung et al., 2011).

The Social Media Sites offer pleasure to their users by connecting and bridging the social relations and making them more outgoing (Steinfield et al., 2008). Especially, the sense of belonging and self-expression that accompany the SNS constitute the main reason why these sites are quite popular with the youth (Hartmann et al., 2017). Escapism derives from our engaging in activities that offer a way out from the problems and pressure that are part of our daily routines (Wu \& Holsapple, 2014).

Nevertheless, the frequent use of the social media can lead to some dire consequences, as well. In this report, we will focus on those that appertain to procrastination.

Procrastination is a form of irrational behavior that is linked to characteristics, such as low self-esteem and impulsiveness (Steel, 2007). According to Sirois and Pychyl (2013), procrastination has to do with a person's failure to self regulate and self control. Thus, they find themselves unable to complete their tasks. Indeed, procrastination is considered to be one of the many causes of anxiety in the workplace (Beheshtifar et al., 2011). Simultaneously, the subsequent the delay that comes with it, entails low academic performance, a decline in self esteem as well as an increase in disappointment and anxiety, not only for the person that procrastinates but also for those that are linked with them.

The failure to live up to their everyday commitments often leads to negative thoughts and feelings as well as anxiety. This happens because the users who procrastinate have to cope with time lapsing and failure to meet deadlines (Flett et al.,2012).

Research has shown that the use of the social media as an educational tool can, indeed, improve both the employees and the students' performance because it offers them the chance to participate in the learning process (Alshuaibi et al., 2018). What makes the users to seek entertainment in the SNS?

1. What consequences does the constant use of the SNS lead to?

2. What makes the educators to seek entertainment in the SNS? 


\section{METHODOLOGY}

In order for these questions to be answered, a questionnaire was distributed to teachers in different schools throughout Greece. The questionnaire is comprised of 30 questions. The first 4 questions concern demographics, namely those about gender, age ( 3 age groups: 26-35, 36-45, over 36), marital status (married, unmarried, divorced) and type of studies. The other 26 questions were used to reflect variables such as pleasure, escapism, socializing as well as procrastination.

The survey took place in May and June 2020. The questionnaires were distributed to the educational centers by e-mail and the principals forwarded it to the educators of schools and educational centers. In total, 323 educators from schools and educational centers participated in the survey. They come from Thessaly, Greece and more particularly from the municipalities of Trikala, Volos, Larisa and Karditsa.

For all the variables, except for the one that concerns job productivity, a Likert 7- like scale was used. Specifically: $1=$ I completely disagree, 2= I disagree, $3=1$ partially disagree, $4=$ neither do I agree, nor I disagree, 5= I partially agree, $6=1$ agree, $7=\mid$ completely agree. As far as the job productivity variable is concerned, a Likert 7-like scale was used as well. But this time, 1= Never, 2= Rarely, 3= Occasionally, 4= Sometimes, 5= Frequently, $6=$ Very frequently, $7=$ Almost always. All the questions concerning variables are closed type ones.

\section{RESULTS}

206 of them are women (63.8\%) and 117 of them are men (36.20\%). The $30.30 \%$ of them (98 people) are aged 26 to $35,32.50 \%$ are $36-46$ years of age (105 people), whereas $37.20 \%$ are over 46 years old (120 people). 134 of them are Bachelor degree holders (41.50\%), 124 (38.40\%) are holders of at least one Master degree, while 65 of them $(20.10 \%)$ are doctorate holders. 187 of those questioned are married (57.90\%), 117 are unmarried (36.20\%), whereas only $5.90 \%$ (19 people) are divorced. The $80.20 \%$ are using Facebook, 31.57\% are using Youtube and $45.20 \%$ are using Instagram.

The data analysis took place through the usage of SPSS V.26. The Cronbach's Alpha was found $a=0.910$. A regression analysis was carried out, concerning whether and to what extent procrastination was predicted by using the Internet for pleasure, usefulness and escapism. The results have shown that the multiple $R$ from the regression analysis is 0.13 which is different from $0, F(4,55)=7.54, p<.001$. In total, all four variables concerned $13 \%$ of the fluctuation in procrastination. Out of them, the fluctuation in procrastination was statistically predicted by escapism $(\beta=.108, t=1.4693, p<$ $.01)$ and socializing $(\beta=.220, t=3.800, p<.001)$. On the contrary, using the Internet for pleasure did not statistically affect the fluctuation in procrastination $(\beta=.020, t=0.281, p>.05)$ and for usefulness $(\beta=-.091, t=-2.601, p<.01)$.

As far as the second question is concerned, the answers were quite neutral $(M=3.82, S D=1.42)$, with the users neither agreeing nor disagreeing. As for usefulness, they remained neutral as well $(M=3.41, S D=1.45)$. Some of them seemed to disagree, though. Socializing seems to be the one variable that was the most controversial, with the highest $S D=1.59$, indicating that the educators' responses differed. As far as $M=3.13$ is concerned, most of those questioned seemed to completely or partially disagree, whereas a significant percentage seemed to partially agree. Last but not least, escapism seemed to be the main motive $(M=4.15, S D=1.44)$, with most the 
participants partially or just agreeing. However, again, some of them remained neutral.

\section{CONCLUSIONS}

As for procrastination, it is evident that it is not connected with the excessive use of the SNS, since most of those questioned seemed to disagree $(M=2.87, \quad S D=1.41)$. The users' procrastination is affected when usefulness, escapism and socializing constitute the main motives behind the use of the social media.

This survey has shown that socializing is the main motive behind the popularity of the SNS, followed by using the Internet for pleasure. The results of this survey coincide with those by Lee \& Ma (2012) indicating that socializing plays the most significant role in making the SNS so popular. Dunne et al., (2010) refer to that type of socializing that has to do with keeping in contact with real-life friends.

\section{REFERENCES}

1. Alshuaibi, M.S.I., Alshuaibi, A.S.I., Shamsudin, F.M., Arshad, D.A. (2018). Use of social media, student engagement, and academic performance of business students in Malaysia. International Journal of Educational Management, 32(4), 625-640.

2. Beheshtifar, M., Hoseinifar H., Moghadam M. (2011). Effect procrastination on workrelated stress. European Journal of Economics, Finance and Administrative Sciences, 38, 59-64.

3. Boyd, D., Ellison, N. (2007). Social Network Sites: Definition, History and Scholarship. Journal of Computer-Mediated Communication, 13(1), 210-230.
4. Cacioppo, J.T., Patrick, W. (2008). Loneliness: Human nature and the need for social connection. New York: W. W. Norton \& Company.

5. Cao, M., Zhang Q., Seydel J. (2005). B2C ecommerce web site quality: an empirical examination. Industrial Management \& Data Systems, 105(5), 645-661.

6. Cheung, C. M.K., Chiu P.Y., Lee M.K.O. (2011). Online social networks: Why do students use facebook? Computers in Human Behavior, 27(4), 1337-1343.

7. De Wulf, K., Schillewaert, N., Muylle, S., Rangarajan, D. (2006). The role of pleasure in web site success. Information \& Management, 43(4), 434-446.

8. Dunne, A., Lawlor, M., Rowley, J. (2010). Young people's use of online social networking sites - a uses and gratifications perspective. Journal of Research in Interactive Marketing, 4(1), 46-58.

9. Flett, G.L., Stainton, M., Hewitt, P., Sherry, S., Lay C. (2012). Procrastination Automatic Thoughts as a Personality Construct: An Analysis of the Procrastinatory Cognitions Inventory. J Rat-Emo Cognitive-Behav Therapy, 30(4), 223-236.

10. Hartmann, P., Apaolaza, V., He J., Barrutia, J.M., Echebarria, C. (2017). The Relationship between Gratifications from Social Networking Site Use and Adolescents' Brand Interactions. Advances in Advertising Research, 7, 29-41.

11. Kim, K.R., Seo E.H. (2015). The relationship between procrastination and academic performance: A meta-analysis. Personality and Individual Differences, 82, 26-33.

12. Kuss, D.J., Griffithis, M.D.(2017). Social Networking Sites and Addiction: Ten Lessons Learned. International Journal of 
Environmental Research and Public Health, 14(3), 311.

13. Lee, C.S., Ma, L. (2012). News sharing in social media: The effect of gratifications and prior experience. Computers in Human Behavior, 28(2), 331-339.

14. Lenhart, A., Smith, A., Anderson, M. (2015). Teens, technology and romantic relationships. Analysis and Policy Observatory.

15. Lin, H., Fan, W., Chau, P.Y.K. (2014). Determinants of users' continuance of social networking sites: A self-regulation perspective. Information \& Management, 51(5), 595-603.

16. Lopez, I., Ruiz, S. (2011). Explaining website effectiveness: the hedonic-utilitarian dual mediation hypothesis. Electronic Commerce Research and Applications, 10(1), 49-58.

17. Mantymaki, M., Riemer, K. (2011). Fun and Friends and Stuff' On the Stickiness of Social Virtual Worlds Among Teenagers. In Proceedings from the 22nd Australiasian Conference on Information Systems ACIS. Sydney, Australia: Association for Information Systems.

18. Oliver, M.B., Raney, A. A. (2011). Entertainment as pleasurable and meaningful: Identifying hedonic and eudaimonic motivations for entertainment consumption. Journal of Communication, 61(5), 984-1004.

19. Ryan, R., Deci, E. (2000). The Darker and Brighter Sides of Human Existence: Basic Psychological Needs as a Unifying Concept. Psychological Inquiry, 11(4), 319-338.

20. Sirois, F.M., Pychyl T. (2013). Procrastination and the priority of short-term mood regulation: Consequences for future self. Social and Personality Psychology Compass, 7(2), 115-127.
21. Somerville, L., Brady, E. (2019). Young people and social networking sites: exploring the views and training opportunities of CAMHS social workers in Ireland. Journal of Social Work Practice, 33(2), 141-155.

22. Steel, P. (2007). The nature of procrastination: A meta-analytic and theoretical review of quintessential selfregulatory failure. Psychological Bulletin, 133(1), 65-94.

23. Steinfield, C., Ellison N., Lampe C. (2008). Social Capital, Self-esteem, and Use of Online Social Network Sites: A longitudinal analysis. Journal of Applied Developmental Psychology, 29, 434-445.

24. Wu, J., Holsapple, C. (2014). Imaginal and emotional experiences in pleasure-oriented it usage: a hedonic consumption perspective. Information \& Management, 51(1), 80-92. 